\title{
Study on milling strategies influence on the quality characteristics in case of composite material
}

\author{
Vasile Ceclan ${ }^{1,}$, Alexandru Popan ${ }^{1}$, Sorin Grozav ${ }^{1}$ and Alina Popan ${ }^{1}$ \\ ${ }^{1}$ Technical University of Cluj Napoca, Manufacturing Engineering Department, ROMANIA
}

\begin{abstract}
Composite materials are widely used today. In this paper we want to conduct a research on the strategy of milling processing of composite materials. A CAD model is required to perform this research. This 3D model must have different areas where the difference between the climb strategy and the conventional strategy can be observed. Special tools and cutting parameters corresponding to the material to be machined are required for this $3 \mathrm{D}$ model.
\end{abstract}

\section{Introduction}

Composite materials are being used more and more today. These materials are found in the top industries, as well as the aeronautical industry, the automotive industry, sports competitions, and other domains. There are airplanes that contain over $50 \%$ of components made of composite materials, due to the ratio between their weight and their strength. This ratio was also analysed by some researchers using finite element analysis method [1]. Also, these materials are used in formula one [2] with very good results. Depending on how the composite materials are obtained, some researchers have made analyses about determining the parameters of unidirectional composite materials [3]. Another research was focused on determining the mechanical properties in the critical section to a tubular material used for the manufacture of bicycle handlebar [4]. All these researches are focused on determining the properties of the materials obtained in a certain form. Another type of research on the composite materials focused on the determination of cutting, some processing on the surface of the material. Very good solution for cutting these materials is water jet cutting [5-7]. Lately there are researches regarding the processing on machines with numerical control of composite materials. Some researchers presented the optimal way of entering the tool into the semi-finished product [8]. For a good roughness of the piece it is necessary to use tools with optimum geometry for the processed material [9-11]. For this reason, we want to make a study about milling the composite material in some complex part. The aim of this research is to conduct a study on milling carbon fibre reinforced composite materials in several directions. Carbon fibre milling is difficult, as this material has very good mechanical properties, but at the same time it is easily malleable.

* Corresponding author: vasile.ceclan@tcm.utcluj.ro 
The accuracy of the parts obtained by milling can be measured by several methods [1213].

\section{Experimental setup}

In the manufacturing industry it is necessary to make 3D complex parts in a short time, and with a good surface quality. For this we used CAD/CAM software in which we need to have a lot of strategies for processing complex 3D shapes with small details. One of this software it is SolidWorks. In this research we used constant $\mathrm{z}$ in climb way of cutting and conventional way of cutting, as is presented in figure 1.
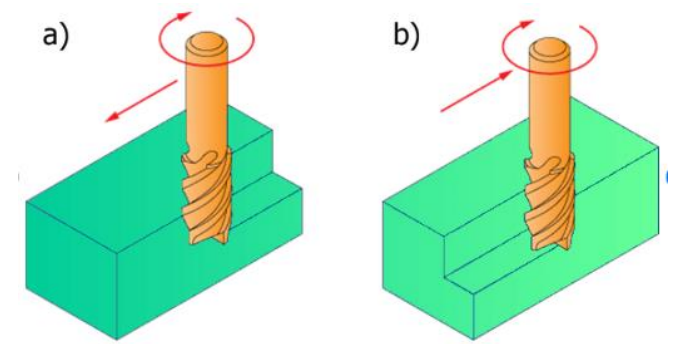

Fig. 1. The milling process principle; a) climb way of cutting b) conventional way of cutting.[14]

\subsection{CAD Model}

We think about one complex 3D shape to have same flat, inclined and variable surfaces, like the model in figure 2 . The dimensions of the part were $50 \times 50 \times 10$.
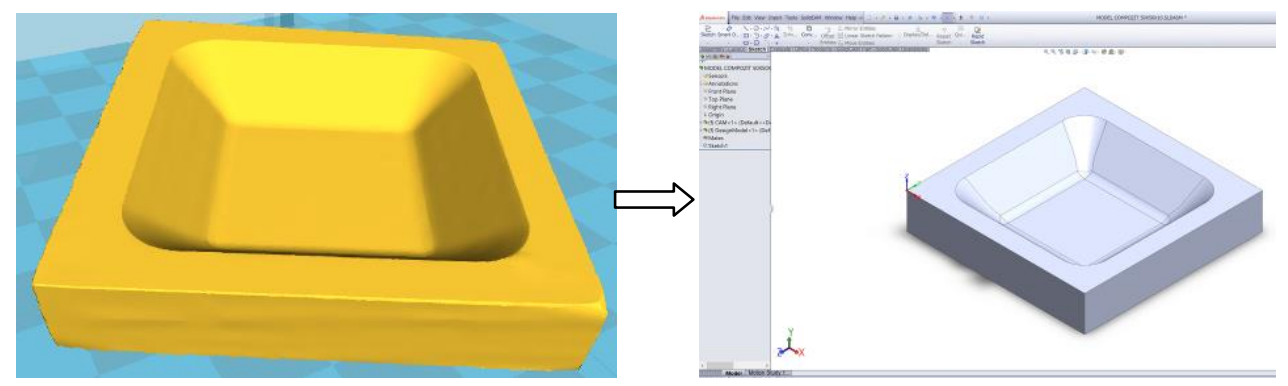

Fig. 2. 3D model of the part

The model has inclined surfaces at an angle of 45 degrees and radius at the corner variable from $5 \mathrm{~mm}$ to $10 \mathrm{~mm}$. At the bottom of the part there is a connection radius of 3 $\mathrm{mm}$, as it presented in figure 3 .
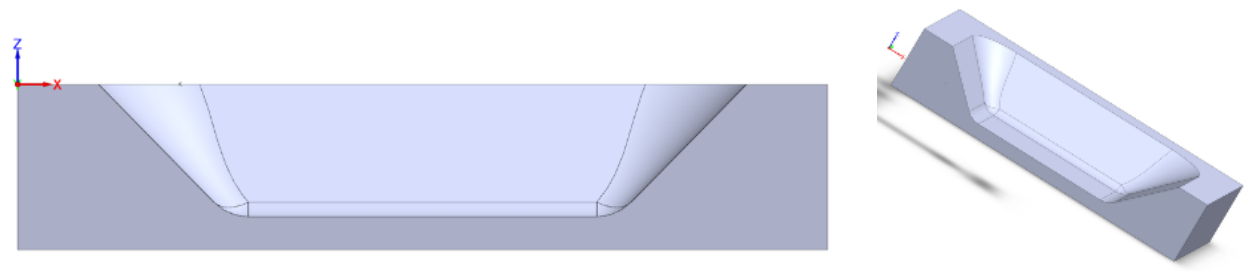

Fig. 3. 3D complex part. 


\subsection{Tooling solutions and process parameters}

For manufacturing this $3 \mathrm{D}$ shape were chosen two tools, one for roughing and one for finishing operation. The part was manufactured using a composite material. The end mills are made from carbide, with 4 flutes.

The process parameters for roughing operation are:

- End mill $6 \mathrm{~mm}$ :

$>$ Feed rate: $400[\mathrm{~mm} / \mathrm{min}]$; cutting speed $500 \mathrm{~m} / \mathrm{min}$;

$>$ Depth of cut: $\mathrm{Ap}=0.5[\mathrm{~mm}]$.

For roughing operation was selected an end mill, as presented in figure 4 .

- Ball nose mill $2 \mathrm{~mm}$ :

$>$ Feed rate: $300[\mathrm{~mm} / \mathrm{min}]$; cutting speed $500 \mathrm{~m} / \mathrm{min}$;

$>$ Depth of cut: $\mathrm{Ap}=0.02[\mathrm{~mm}]$.

For finishing operations was chosen a ball mill, as in figure 5 .

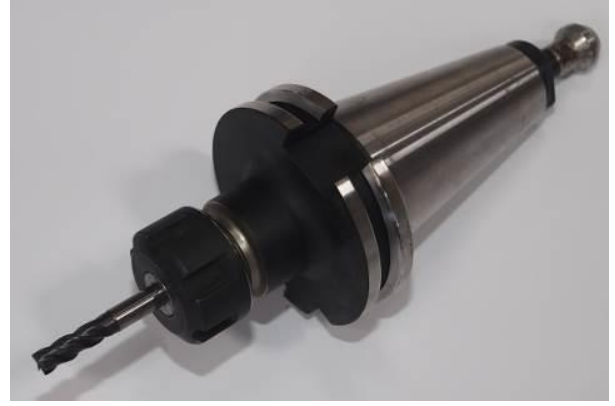

Fig. 4. The tool used for roughing operation.

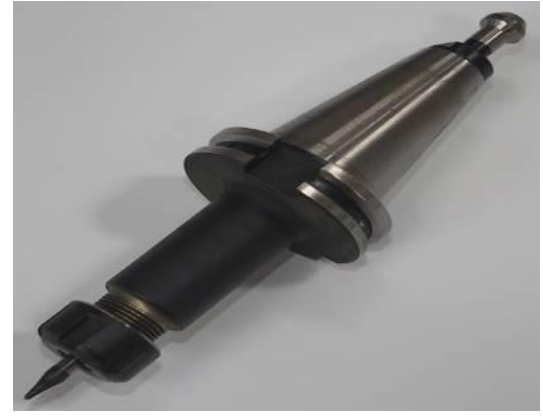

Fig. 5. The tool used for finishing operation.

\subsection{CAM Model}

To manufacture the part was used the constant $\mathrm{z}$ strategy, in half of model with climb cutting, and the other side with conventional cutting. This strategy was applied in order to study the surface part in the case of modifying the way of cutting.

In figure 7 it can be seen the trajectory of the tool on the part. It can be observed the movement of the tools in region of the variable radium on the 3D shape.

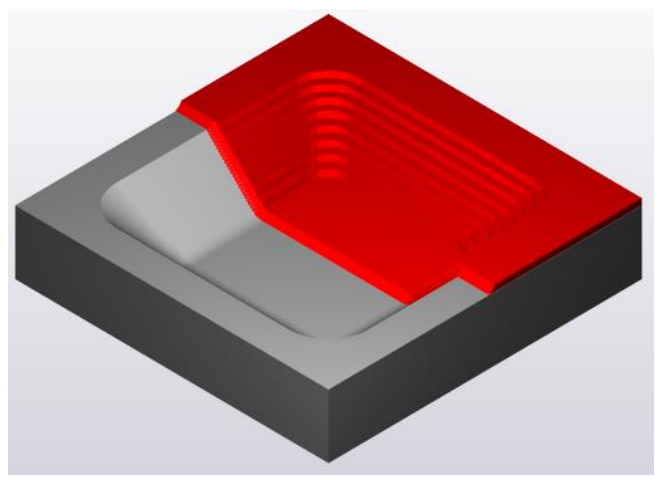

Fig. 6. The way of cutting.

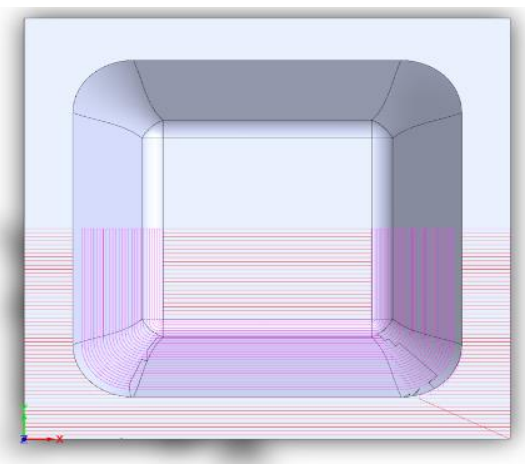

Fig. 7. The trajectory of the tool. 


\subsection{Material}

For this research we used a composite material reinforced with carbon fibres. The fibre was oriented in several directions and layers. This material was processed using water jet cutting technology, as can be seen in figure 8 . The water jet cutting it is a good solution to obtain a sample from a material without influencing the material properties and without affecting the material structure.
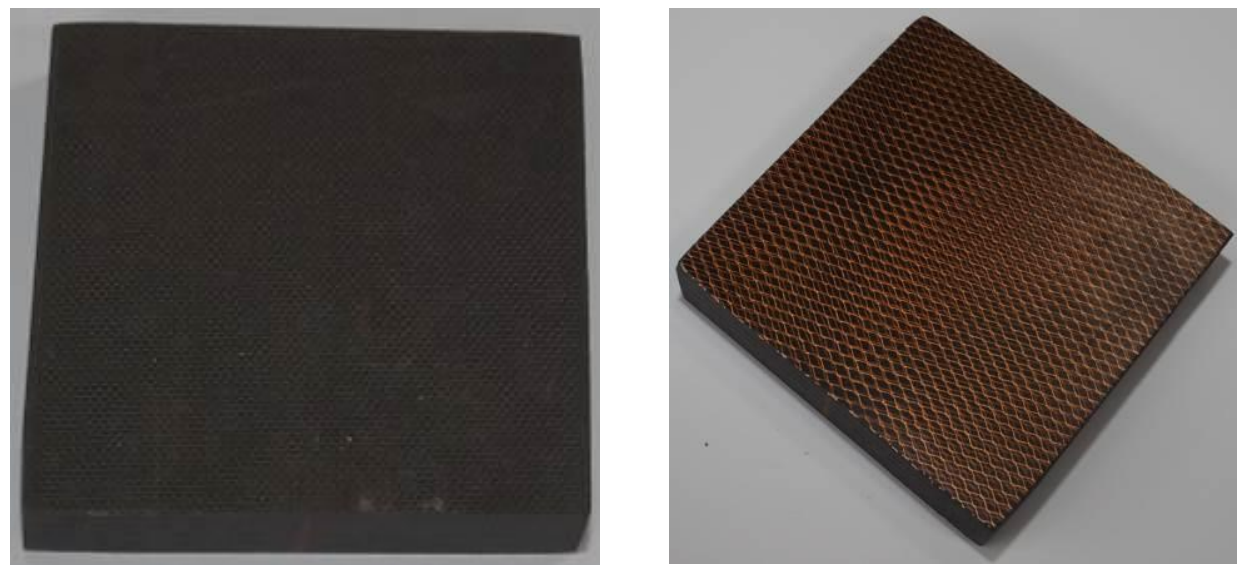

Fig. 8. Composite material reinforced with carbon fibres.

\subsection{CNC machining}

A Haas CNC manufacturing centre was used to process this part of composite material. In figure 9 one can observe the semi-finished product fixed in the CNC machine. The next step is to choose the origin of the part. In figure $b$ it can be observed that it is used a cooling liquid, to have a better performance of the tools. In the last image of this figure it is presented the final part of composite material.

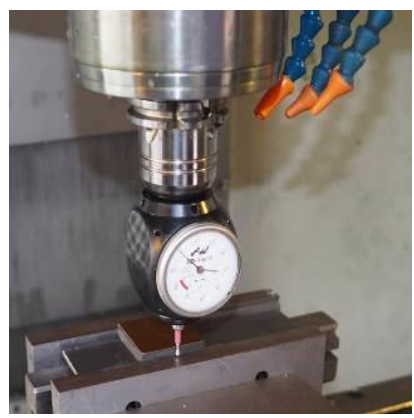

a)

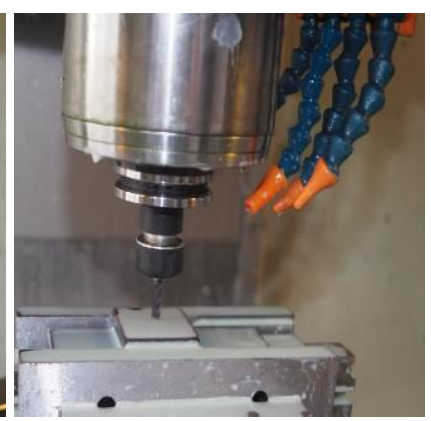

b)

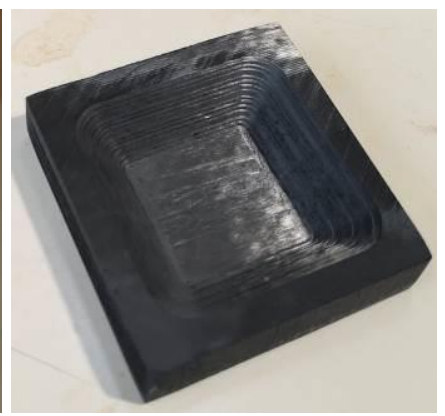

c)

Fig. 9. Steps of $\mathrm{CNC}$ machining. 


\section{Results and Discussion}

Following these researches, the objective is to study the influence of processing strategies on the accuracy of the part and its roughness. As a result of these investigations we want to see which of the two milling strategies is recommended for achieving flat or inclined surfaces. Another purpose of the present research is to see how the composite materials reinforced with carbon fibres are milled.

\subsection{Influence of the manufacturing strategy on dimensional accuracy}

The resulting part was scanned with a wire mesh system. The 3D model was compared to the one obtained from scans, in specialized software GOM. In figure 10 it is presented a comparison between 3D and mash model.

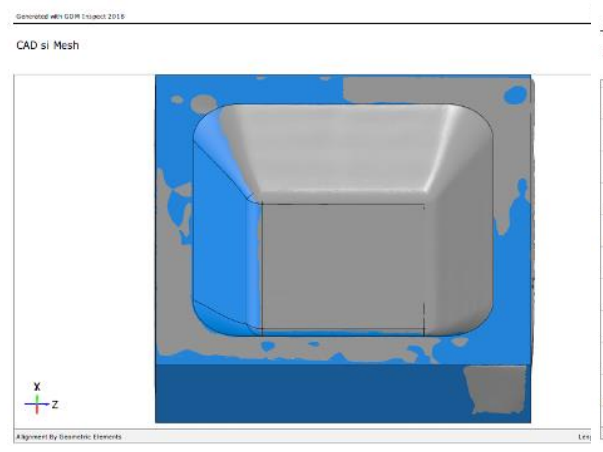

Fig. 10. Comparison between 3D model and mesh.

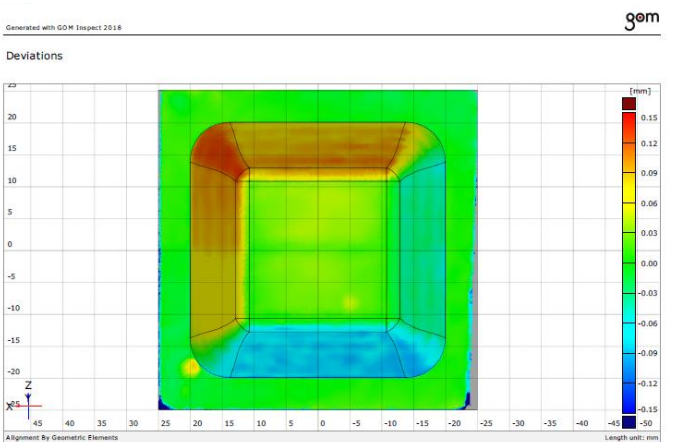

Fig. 11. Deviation of the part.

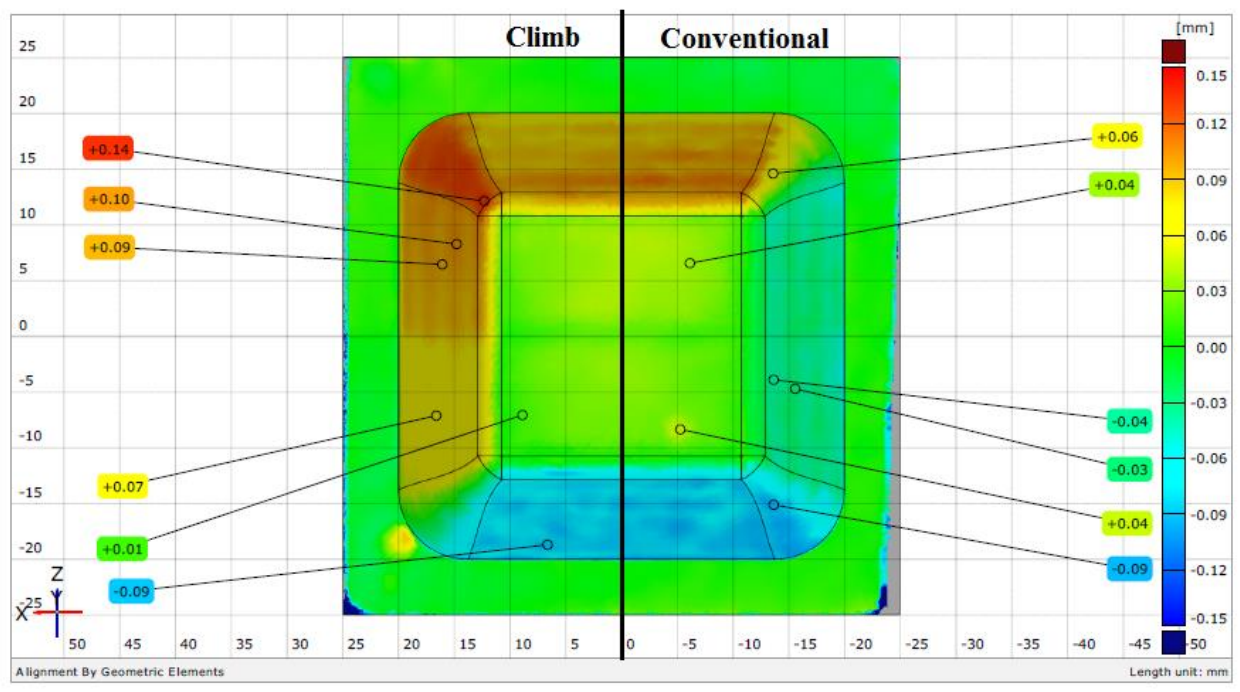

Fig. 12. Dimensional accuracy on the two zones.

To have a good dimensional accuracy the model was cut in the cross section and it shows the deviation in two zones of the pieces (Climb zone; Conventional zone). It can be seen that deviations from the $3 \mathrm{D}$ model are from -0.09 to +0.14 . 
In order to be able to achieve a better agreement of the results obtained from the scans, we have realized the section of the piece with two separation plans. The first one was made at 90 degrees from the axis of delimitation of the two milling zones. The second section was made on the diagonal of the piece, in order to better study the influence of the radius variation.
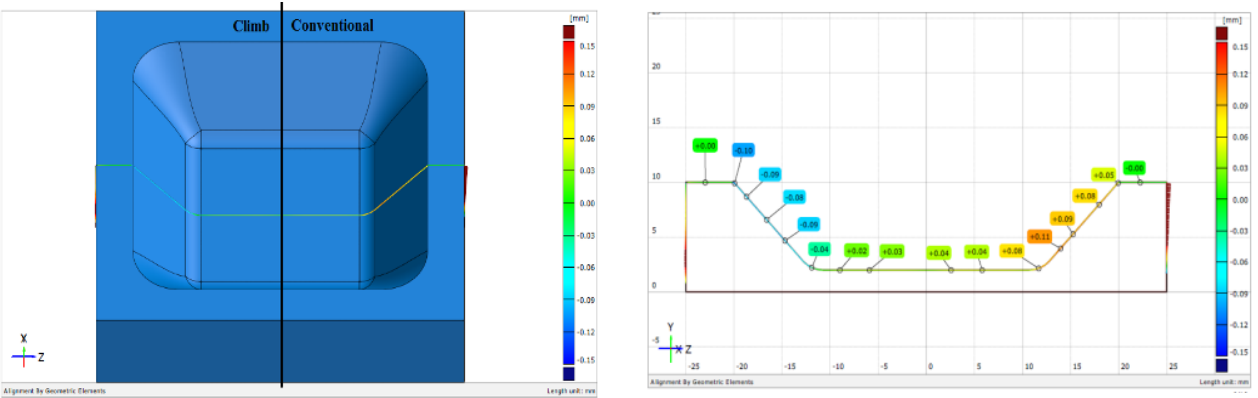

Fig. 13. Dimensional accuracy on the two zones at $90^{\circ}$
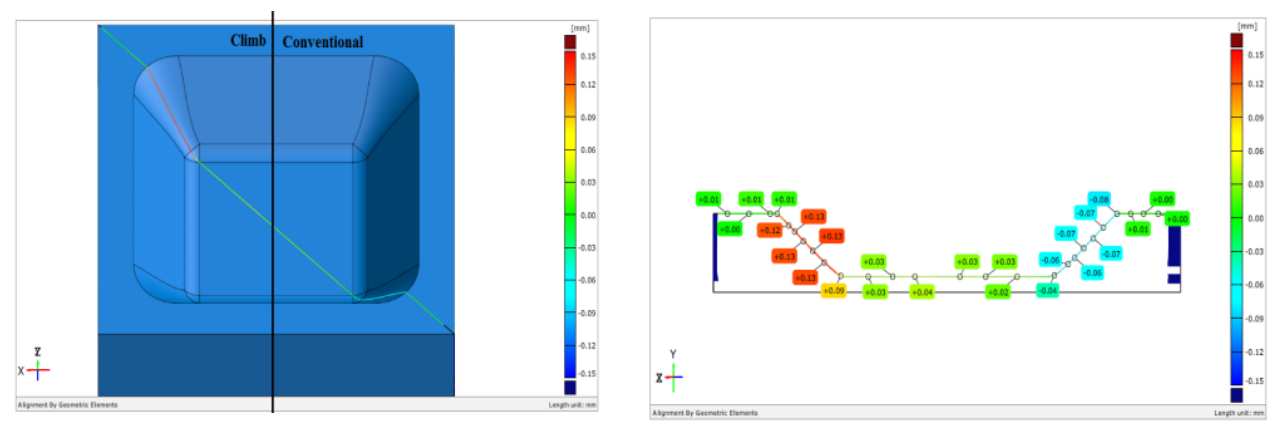

Fig. 14. Dimensional accuracy on the two zones - diagonal section

\subsection{Influence of the strategy on the roughness}

Figure 15 shows the measurement of the roughness of the piece at different points. The measurements were made on two planes, horizontally and inclined. This was made in order to be able to specify which of the two processing strategies, climb or conventional it is a better solution for milling the composite material reinforced with carbon fibres. On each area of the part were made 5 measurements of the surface roughness.
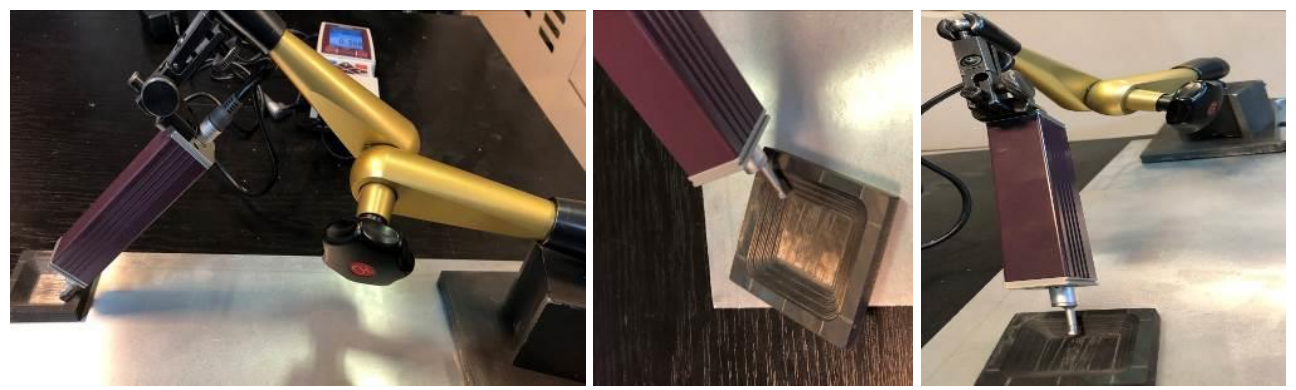

Fig. 15. Measurement of the surface roughness. 
In table 1 are presented the roughness values, $\mathrm{Ra}$, for the horizontal area where we can see that it varies between $4.714 \mu \mathrm{m}$ and $1.797 \mu \mathrm{m}$. In zone B the roughness has a smaller value than in the rest of zone, which is why we can say that carbon fibre was in that direction.

On the inclined surface it can observed that the roughness value $R_{a}$ is smaller than the one of the horizontal surfaces and the value of this it is between 0.549 and 0.968 .

Table. 1 Roughness values, measured on the part surface

\begin{tabular}{|c|c|c|c|c|c|c|c|}
\hline zooen A & & ${ }^{\mathrm{R} 1}$ & & \multicolumn{2}{|c|}{$\mathrm{R}_{\mathrm{a}}$ Horizontal } & \multicolumn{2}{|c|}{$\begin{array}{l}\mathrm{R}_{\mathrm{a}} \text { Surface } \\
\text { inclined }\end{array}$} \\
\hline \multirow{6}{*}{ Clinb } & \multirow{6}{*}{ Comrational| } & \multirow{6}{*}{ 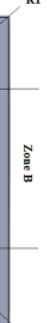 } & Method & Climb & Conv. & Climb & Conv. \\
\hline & & & Zone A & 3,566 & 3,847 & 0,968 & 0,766 \\
\hline & & & Zone B & 1,797 & 2,322 & 0,855 & 0,654 \\
\hline & & & Zone $\mathrm{C}$ & 2,413 & 4,053 & 0,804 & 0,693 \\
\hline & & & R1 & 3,386 & 3,881 & 0,884 & 0,712 \\
\hline & & & $\mathbf{R 2}$ & 4,283 & 4,714 & 0,862 & 0,549 \\
\hline
\end{tabular}
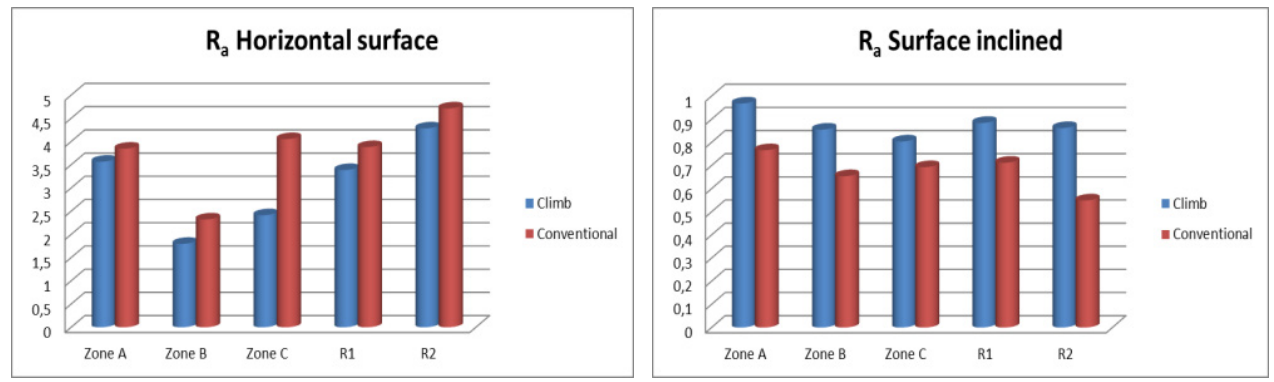

Fig. 16. Results of the roughness.

In figure 16 it is presented the comparison between climb strategy and conventional strategy on the horizontal surface and also on the inclined surface.

\section{Conclusions}

Milling of reinforced composite materials in several directions and on several layers with carbon fibre is possible. After this study, it can be concluded that the surface roughness of the part it is better if the conventional strategy is used on the horizontal surfaces. On the inclined surfaces it is suitable to use the climb strategy to have a better Ra.

Another conclusion obtained from these researches is that if the part it is milled along the carbon fibre, we will get a very good roughness.

Regarding the accuracy of the part it can be observed that this varies from -0.09 to +0.14 . In the area where the part was manufactured using climb strategy, were obtained positive values (with "+"), while in the area where it was manufactured with conventional strategy, we have negative values (with "-"). Another important conclusion is that the carbon fibre reinforced with composite materials are milled differently comparing with metallic materials. In the case of metal part, the accuracy is better in the case of the climb strategy, while for composite material part the accuracy is better in the conventional milling area. This is achieved due to the fact that in the climb milled area with the carbon fibre is 
removed from the material, while in the conventional milled area the carbon fibre is pressed into the material.

In conclusion we can say that in the horizontal area the accuracy of the part it is better than the accuracy from the inclined area. The variation of the radius is not having a big influence on the accuracy of the part. The accuracy of the part it is better in the radius area if it is milled by the conventional strategy.

The results presented in this paper were obtained in the framework of the GNaC 2018 ARUT grant research, contract no. 3215/06.02.2019, with the financial support of the TUCN and the Horizon 2020, DiCoMI project, contract no 778068 ".

\section{References}

1. E. Sabau, A. Popescu, and C. Vilau, MATEC Web of Conferences, Vol 137 (2017)

2. P.Bere and C.Neamtu, Central European Journal of Engineering, Vol 4, Issue 2, pg 148-154 (2014)

3. E. Sabau, N. Balc, and, P.1 Bere, Advanced Engineering Forum, Trans Tech Publications, Vols. 8-9, pp. 309-316, (2013).

4. P. Bere, M.C. Dudescu, N. Balc, P. Berce, A.M. Iurian and O. Nemes, Materiale Plastice, Vol 51, Issue 2, pg 145-149 (2014)

5. A. Miron, N. Bâlc, A. Popan, C. Borzan, P. Bere, Academic Journal of Manufacturing Engineering, Vol 11, Issue 2 (2013)

6. A. Popan, N. Balc, A. Carean, A. Luca, V. Ceclan, Academic Journal of Manufacturing Engineering, Vol 9, Issue 3 (2011)

7. A. Popan, G. Contiu, RI. Campbell, MATEC Web of Conferences, Vol 137, EDP Sciences (2017)

8. M. Hu, W. Ming, Q. An, M. Chen, Ceramics International, Vol 45, Issue 8, pg. 1058110588, (2019)

9. AH. Seikh, BB. Mandal, A. Sarkar, M. Baig, N. Alharthi, B. Alzahrani, International Journal of Mechanical and Materials Engineering, Vol 14, (2019)

10. J. Jerzy, I. Kuric, S. Grozav, V. Ceclan, Academic Journal of Manufacturing Engineering, Vol. 12, Issue 1, pp.56-60, (2014)

11. Chih-Ching Lo, International Journal of Machine Tools and Manufacture, Vol 40, Issue 3, pg. 307-326. (2000)

12. Fulea L., Bulgaru M, Borzan M, BocăneȚ V., 11-th International Conference MTeM 17-19 oct. (2013)

13. V.Bocanet, M. Bulgaru and V.Pop, MATEC Web of Conferences, Vol 137 (2017)

14. G. Pinkowski, W. Szymański, T. Nosowski, Annals of Warsaw University of Life Sciences - SGGW Forestry and Wood Technology, No 79, pg.164-169 (2012) 